\title{
UPAYA MENINGKATKAN KINERJA GURU DALAM MENYUSUN RPP MELALUI SUPERVISI AKADEMIK SECARA PERIODIK
}

\author{
Sarwantinah \\ SD Negeri 2 Gambiranom \\ sarwantinah123@gmail.com
}

\begin{abstract}
Abstrak
Penelitian ini bertujuan untuk meningkatkan kompetensi guru dalam menyusun RPP melalui supervisi akademik secara periodik di SD Negeri 2 Gambiranom. Penelitian ini merupakan Penelitian Tindakan Sekolah yang dilaksanakan dalam 2 (dua) siklus. Subjek penelitian ini yaitu guru SD Negeri 2 Gambiranom yang berjumlah 8 orang. Pengumpulan data dalam penelitian dilakukan melalui observasi. Analisis data dilakukan dengan 3 (tiga) tahapan meliputi: reduksi data, penyajian data dan penarikan kesimpulan atau verifikasi. Berdasarkan hasil penelitian, kondisi awal nilai rata-rata kinerja guru dalam menyusun RPP yaitu 67,1 dengan kualifikasi Cukup dengan jumlah guru memperoleh nilai Baik 25\% ke kondisi siklus I nilai rata-rata nilai 77.9 dengan kualifikasi Baik dengan jumlah guru memperoleh nilai Amat Baik dan Baik 62.5\%. Meningkat lagi ke kondisi akhir pada siklus II nilai ratarata nilai 86,3 dengan kualifikasi Baik dengan jumlah guru memperoleh nilai Amat Baik dan Baik 100\% di SD Negeri 2 Gambiranom semester 1 Tahun Pelajaran 2018/2019. Oleh karena itu, dapat disimpulkan bahwa supervisi akademik secara periodik dapat meningkatkan kompetensi guru dalam menyusun RPP di SD Negeri 2 Gambiranom semester 1 Tahun Pelajaran 2018/2019.
\end{abstract}

Kata kunci: Kompetensi guru, RPP, supervisi akademik

\begin{abstract}
This study aims to improve teacher competence in preparing lesson plans through periodic academic supervision at SD Negeri 2 Gambiranom. This research is a school action research conducted in 2 (two) cycles. The subjects of this study were 8 teachers of SD Negeri 2 Gambiranom. Data collection in the study was carried out through observation. Data analysis was carried out in 3 (three) stages including: data reduction, data presentation and drawing conclusions or verification. Based on the results of the study, the initial condition of the average value of teacher performance in preparing RPP is 67.1 with sufficient qualifications with the number of teachers getting a Good score of $25 \%$ to the condition of the first cycle the average value is 77.9 with Good qualifications with the number of teachers getting Very Good scores and Good 62.5\%. It increased again to the final condition in cycle II with an average value of 86.3 with Good qualifications with the number of teachers obtaining 100\% Very Good and Good scores at SD Negeri 2 Gambiranom semester 1 of the 2018/2019 academic year. Therefore, it can be concluded that periodic academic supervision can improve teacher competence in preparing lesson plans at SD Negeri 2 Gambiranom semester 1 of the 2018/2019 academic year.
\end{abstract}

Keywords: teacher competence, lesson plans, academic supervision

\section{PENDAHULUAN}

Menurut Undang-Undang No. 14 tahun 2005 tentang Guru dan Dosen pasal 10 ayat (1) kompetensi guru meliputi kompetensi pedagogik, kompetensi kepribadian, kompetensi sosial, dan kompetensi profesional yang diperoleh melalui pendidikan profesi. Salah satu kompetensi yang wajib dimiliki oleh guru adalah kompetensi pedagogik. Dalam hal ini kompetensi pedagogik adalah kemampuan mengelola pembelajaran peserta didik. Kompetensi ini dapat dilihat dari kemampuan merencanakan program pembelajaran, kemampuan melaksanakan program pembelajaran, dan kemampuan melaksanakan evaluasi hasil belajar atau penilaian (Sulastri et al., 2014).

Setiap guru pada satuan pendidikan berkewajiban menyusun perangkat 
pembelajaran, antara lain meliputi RPP secara lengkap dan sistematis agar pembelajaran berlangsung secara interaktif, inspiratif, menyenangkan, menantang, memotivasi peserta didik untuk berpartisipasi aktif, serta memberikan ruang yang cukup bagi prakarsa, kreativitas, dan kemandirian sesuai dengan bakat, minat, dan perkembangan fisik serta psikologis peserta didik (Rahayu, 2016). Guru harus terus berkembang dan meningkatkan kompetensinya (Nurgiansah \& Sukmawati, 2020).

RPP (Rencana Pelaksanaan Pembelajaran) adalah suatu perencanaan pembelajaran yang sangat penting untuk mengarahkan kegiatan belajar untuk mencapai tujuan pembelajaran dan kompetensi yang harus dimiliki siswa. Menurut Hernawan (2009:9.7) Rencana Pelaksanaan Pembelajaran merupakan kegiatan merumuskan tujuan-tujuan apa yang ingin di capai oleh suatu kegiatan pembelajaran, cara apa yang digunakan untuk menilai pencapaian tujuan tersebut, materi atau bahan apa yang disampaikan, bagaimana cara menyampaiakan, serta media atau alat apa yang diperlukan untuk mendukung pembelajaran tersebut.

Menurut Depdiknas (2008:5) di dalam rencana pembelajaran mencakup standar kompetensi, kompetensi dasar, materi pokok/pembelajaran, kegiatan pembelajaran, indikator, penilaian seorang guru. Penyusunan perencanaan program pengajaran memegang peranan yang sangat penting dalam pengembangan kurikulum, karena menentukan langkah pelaksanaan pembelajaran dan evaluasi belajar untuk peserta didik (Mahmuda, 2013). Perencanaan pembelajaran yang dibuat guru merupakan acuan atau pedoman tentang kegiatan-kegiatan yang akan dilakukan selama kegiatan pembelajaran berlangsung. Sudjana (2012: 34) juga mengatakan bahwa perencanaan pembelajaran adalah rancangan tentang apa yang akan dikerjakan guru dalam melaksanakan pembelajaran.

Dengan kata lain perencanaan pembelajaran adalah proyeksi atau perkiraan kegiatan yang akan dilaksanakan guru pada saat guru membelajar peserta didik (Oviana, 2013). Perencanaan pembelajaran yang dibuat guru dituangkan dalam bentuk rencana pelaksanaan pembelajaran. Yaumi (2013: 4) menyatakan bahwa keefektifan pembelajaran merupakan suatu ukuran sejauh mana para guru menyadari tentang tanggung jawab mereka. Jika guru gagal mengelola rencana pembelajaran secara tepat, maka peserta didik pasti gagal untuk mencapai tingkat penguasaan yang dibutuhkan dan akhirnya pelaksanaan pembelajaran menjadi tidak efektif. Sudjana (2012: 35) menyatakan bahwa menjadi sebuah kesalahan besar apabila pada waktu melaksanakan pembelajaran guru tidak membawa RPP apalagi jika guru tidak membuat RPP.

Realita dilapangan berdasarkan hasil diskusi yang dilakukan peneliti terhadap guru di SD Negeri 2 Gambiranom, rendahnya kinerja dan wawasan guru disebabkan oleh 1) rendahnya kesadaran guru untuk belajar, 2) kurangnya kesempatan guru mengikuti pelatihan, baik secara regional maupun nasional, 3) kurang efektifnya PKG, serta 4) tidak tercapainya tujuan supervisi pendidikan dalam memperbaiki proses pembelajaran. Oleh karena itu, agar tercapai kompetensi yang diharapkan sekolah harus melaksanakan pembinaan terhadap guru dimana salah satunya melalui supervisi akademik yang dilakukan secara periodik.

Menurut Sahertian (2000:19) supervisi adalah usaha memberi layanan kepada guru baik secara individual maupun secara kelompok dalam usaha memperbaiki pengajaran. Kata kunci dari pemberi supervisi pada akhirnya ialah 
memberikan layanan dan bantuan. Selanjutnya, Suharsimi Arikunto (2004:11) mengemukakan bahwa supervisi adalah bantuan dalam pengembangan situasi belajar mengajar agar memperoleh kondisi yang lebih baik. Sahertian (2000:19) tujuan supervisi akademik adalah memberikan layanan dan bantuan untuk meningkatkan kualitas mengajar guru di kelas yang pada gilirannya untuk meningkatkan kualitas belajar siswa Bukan saja memperbaiki kemampuan mengajar tetapi juga mengembangkan potensi kualitas guru.

Menurut Alfonso, Firth, dan Neville (1981) Supervisi akademik yang baik adalah supervisi akademik yang mampu berfungsi mencapai multi tujuan tersebut di atas. Tidak ada keberhasilan bagi supervisi akademik jika hanya memperhatikan salah satu tujuan tertentu dengan mengesampingkan tujuan lainnya. Ada bermacam-macam teknik supervisi akademik dalam upaya pembinaan kemampuan guru. Dalam hal ini meliputi pertemuan staf, kunjungan supervisi, buletin profesional, perpustakaan profesional, laboratorium kurikulum, penilaian guru, demonstrasi pembelajaran, pengembangan kurikulum, petunjuk pembelajaran, darmawisata, lokakarya, kunjungan antarkelas, bacaan profesional, dan survei masyarakat sekolah.

Untuk memperbaiki kinerja dan wawasan guru dalam pembelajaran di SD Negeri 2 Gambiranom, sekolah melaksanakan penelitian tindakan yang berkaitan dengan permasalahan di atas. Karena keterbatasan peneliti, maka penelitian ini hanya difokuskan pada supervisi edukatif saja sehingga judul penelitian tindakan tersebut adalah " Meningkatkan Kinerja Guru Dalam menyusun RPP melalui Supervisi Akademik Secara Periodik Pada Sekolah Dasar Negeri 2 Gambiranom"

\section{METODE PENELITIAN}

Waktu penelitian ini dimulai dari bulan Juli 2018 sampai Desember 2018 pada Tahun Pelajaran 2018/2019. Lokasi penelitian ini yaitu di SD Negeri 2 Gambiranom. Penentuan tempat penelitian mempertimbangkan beberapa hal diantaranya: a) dalam melaksanakan kegiatan penelitian tidak meninggalkan tugas. b) pelaksanaan penelitian berpengaruh terhadap proses penyusunan RPP pada guru-guru SDN 2 Gambiranom. Subjek penelitian ini adalah guru-guru SDN 2 Gambiranom yang berjumlah 8 orang guru. Objek penelitian ini yaitu kinerja guru dalam penyusunan RPP secara berkelompok.

Teknik pengumpulan data dalam penelitian ini yaitu wawancara, observasi dan dokumentasi. Selanjutnya, indicator keberhasilan kinerja tindakan penelitian ini yaitu 1) Rata-rata persentase keaktifan guru mencapai $80 \%$ atau sebanyak 6 dari 8 guru yang menjadi subjek penelitian, 2) $80 \%$ guru tuntas dalam menyusun RPP.

Penelitian ini berbentuk Penelitian Tindakan Sekolah (School Action Research yaitu sebuah penelitian yang merupakan kerjasama antara peneliti dan guru untuk meningkatkan kemampuan guru agar menjadi lebih baik dalam menyusun rencana pelaksanaan pembelajaran. Penelitian Tindakan Kelas merupakan penelitian yang mengangkat masalahmasalah yang aktual (Nurgiansah, 2021).

Penelitian direncanakan menggunakan tindakan daur ulang seperti yang dikembangkan oleh Suharsimi Arikunto (2010:17) dengan menggunakan langkahlangkah: perencanaan, pelaksanaan, pengamatan dan refleksi. Keempat kegiatan tersebut saling terkait dan secara urut membentuk sebuah siklus. Penelitian Tindakan Sekolah merupakan penelitian yang bersiklus, artinya penelitian dilakukan secara berulang dan berkelanjutan sampai tujuan penelitian dapat tercapai. Berikut adalah gambaran pelaksanaan penelitian yang dimaksud : 


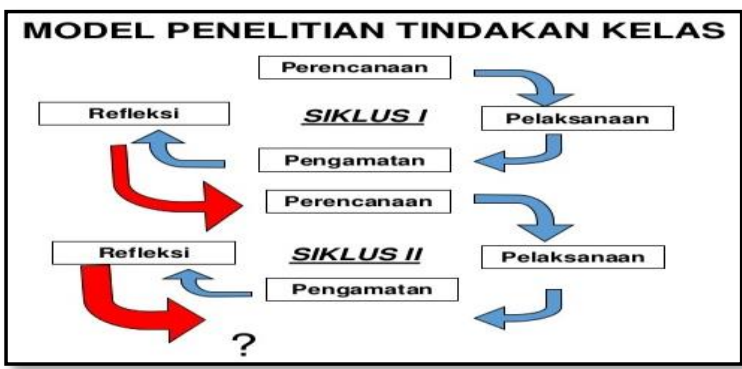

Gambar 1. Pelaksanaan Penelitian Tindakan

\section{HASIL PENELITIAN DAN PEMBAHASAN Hasil Penelitian Deskripsi Kondisi Awal}

Pada kondisi awal penilaian kompetensi guru dalam menyusun RPP kurang memuaskan. Hal ini disebabkan kurangnya pembinaan dan pelatihan untuk meningkatkan kompetensi guru tersebut. Adapun tabel penilaian kompetensi guru dalam menyusun RPP pada kondisi awal dapat disajikan pada tabel berikut:

Tabel 1. Penilaian Dokumen RPP Kondisi Awal

\begin{tabular}{|c|c|c|}
\hline No & Aspek yang Dinilai & Hasil \\
\hline 1 & A & 66,3 \\
\hline 2 & B & 66.3 \\
\hline 3 & C & 68.8 \\
\hline \multicolumn{2}{|c|}{ Rata-rata } & 68.3 \\
\hline \multicolumn{2}{|c|}{ Kualifikasi } & Cukup \\
\hline
\end{tabular}

Sedangkan grafik penilaian dokumen RPP dinyatakan sebagai berikut:

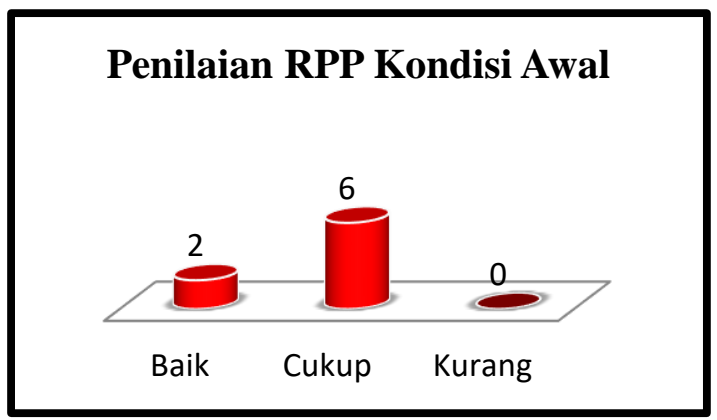

Gambar 1. Grafik Penilaian Dokumen RPP Kondisi Awal

Hasil penilaian RPP menunjukkan nilai rata-rata nilai 67,1 dengan kualifikasi Cukup. Jumlah guru dengan nilai Baik ada 2 orang (25\%), dan nilai Cukup 6 orang
(75\%). Melihat kenyataan tersebut, maka peneliti sebagai Kepala Sekolah melaksanakan penelitian tindakan sekolah melalui penerapan supervisi akademik secara periodik yang dilaksanakan pada siklus I.

\section{Siklus I}

Siklus I dilaksanakan melalui tahap perencanaan, pelaksanaan tindakan, observasi, dan evaluasi. Berdasarkan hasil observasi yang dilakukan oleh peneliti pada tindakan siklus I, diperoleh data sebagai berikut :

Tabel 2. Penilaian Dokumen RPP Siklus I

\begin{tabular}{|c|c|c|}
\hline No & Aspek yang Dinilai & Hasil \\
\hline 1 & $\mathrm{~A}$ & 80,0 \\
\hline 2 & $\mathrm{~B}$ & 78,8 \\
\hline 3 & $\mathrm{C}$ & 75,0 \\
\hline \multicolumn{2}{|c|}{ Rata-rata } & 77.9 \\
\hline \multicolumn{2}{|c|}{ Kualifikasi } & Baik \\
\hline
\end{tabular}

Sedangkan grafik penilaian dokumen RPP dinyatakan sebagai berikut:

\section{Penilaian RPP Siklus I}

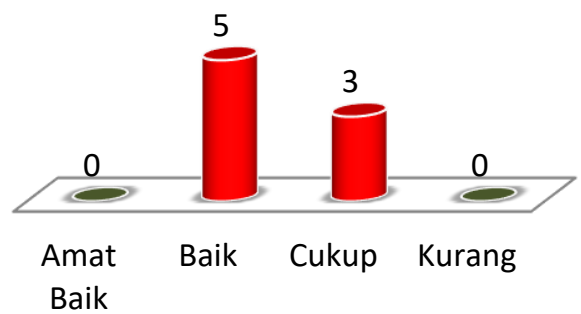

Gambar 2. Grafik Penilaian Dokumen RPP Siklus I

Hasil penilaian RPP pada siklus I menunjukkan nilai rata-rata nilai 77.9 dengan kualifikasi Baik. Jumlah guru dengan nilai Amat Baik ada 0 orang (0\%), nilai Baik ada 5 orang (62,5\%), dan nilai Cukup 3 orang (37.5\%). Melalui supervisi akademik secara periodik dapat meningkatkan kompetensi guru dalam menyusun RPP dari kondisi awal nilai ratarata 67,1 dengan kualifikasi Cukup dengan 
jumlah guru memperoleh nilai Baik 25\% ke kondisi siklus I nilai rata-rata nilai 77.9 dengan kualifikasi Baik dengan jumlah guru memperoleh nilai Amat Baik dan Baik $62.5 \%$ di SD Negeri 2 Gambiranom semester 1 Tahun Pelajaran 2018/2019.

Kompetensi guru SD Negeri 2 Gambiranom dalam menyusun RPP pada siklus I sudah menunjukkan peningkatan, namun belum mencapai indikator kinerja dalam penelitian tindakan sekolah ini, yaitu belum semua guru SD Negeri 2 Gambiranom memperoleh kualifikasi Amat Baik (A) dan Baik (B) pada hasil penilaian RPP sehingga peneliti memutuskan untuk melanjutkan tindakan ke siklus II.

\section{Siklus II}

Siklus II dilaksanakan dalam 3 pertemuan. Pertemuan pertama dan kedua digunakan untuk penerapan supervisi akademik secara periodik dengan pertemuan individual, dan pertemuan ketiga untuk penilaian. Berdasarkan observasi peneliti pada siklus II, secara umum kompetensi guru dalam menyusun RPP menunjukkan peningkatan. Hal ini terlihat dari peningkatan hasil penilaian dokumen RPP yang dilakukan peneliti. Berikut ini adalah hasil supervisi penilaian kompetensi guru pada siklus II.

Tabel 3. Penilaian Dokumen RPP Siklus II

\begin{tabular}{|c|c|c|}
\hline No & Aspek yang Dinilai & Hasil \\
\hline 1 & A & 86.3 \\
\hline 2 & B & 86.9 \\
\hline 3 & C & 85.6 \\
\hline \multicolumn{3}{|c|}{ Rata-rata } \\
\hline Kualifikasi & Baik \\
\hline
\end{tabular}

Sedangkan grafik penilaian dokumen RPP dinyatakan sebagai berikut:

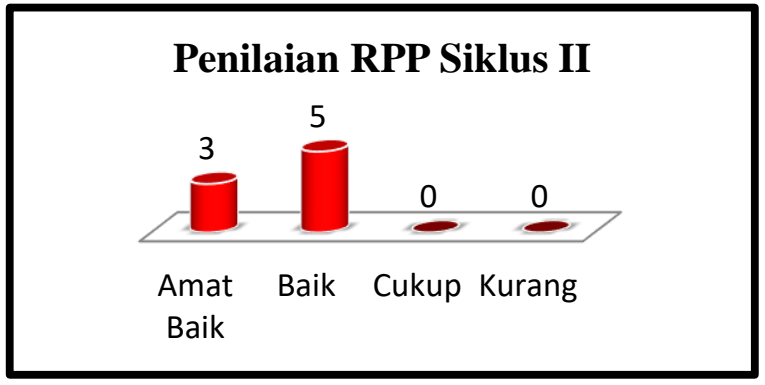

Gambar 3. Grafik Penilaian Dokumen RPP Siklus II

Hasil penilaian RPP menunjukkan nilai rata-rata nilai 86,3 dengan kualifikasi Baik. Jumlah guru dengan nilai Amat Baik ada 3 orang $(37.5 \%)$ dan nilai Baik ada 5 orang (62.5\%). Kompetensi guru SD Negeri 2 Gambiranom dalam menyusun RPP pada siklus II sudah mencapai indikator kinerja dalam penelitian tindakan sekolah ini, yaitu semua guru SD Negeri 2 Gambiranom minimal masuk kualifikasi Amat Baik (A) atau Baik (B) pada penilaian RPP. Oleh karena itu, peneliti memutuskan untuk menghentikan tindakan penelitian sampai pada siklus II.

\section{Pembahasan}

Pada kondisi awal, peneliti belum melaksanakan supervisi akademik secara periodik Hasil penilaian RPP menunjukkan nilai rata-rata nilai 67,1 dengan kualifikasi Cukup. Jumlah guru dengan nilai Baik ada 2 orang (25\%), dan nilai Cukup 6 orang (75\%). Pada siklus I, peneliti sudah melaksanakan supervisi akademik secara periodik Hasil penilaian RPP menunjukkan nilai rata-rata nilai 77.9 dengan kualifikasi Baik. Jumlah guru dengan nilai nilai Baik ada 5 orang $(62,5 \%)$, dan nilai Cukup 3 orang $(37.5 \%)$.

Pada siklus II, peneliti melaksanakan supervisi akademik secara periodik Hasil penilaian RPP menunjukkan nilai rata-rata nilai 86,3 dengan kualifikasi Baik. Jumlah guru dengan nilai Amat Baik ada 3 orang (37.5\%) dan nilai Baik ada 5 orang (62.5\%). Melalui supervisi akademik secara periodik dapat meningkatkan 
kompetensi guru dalam menyusun RPP dari kondisi awal nilai rata-rata 67,1 dengan kualifikasi Cukup dengan jumlah guru memperoleh nilai Baik 25\% ke kondisi siklus I nilai rata-rata nilai 77.9 dengan kualifikasi Baik dengan jumlah guru memperoleh nilai Amat Baik dan Baik 62.5\%. Meningkat lagi ke kondisi akhir pada siklus II nilai rata-rata nilai 86,3 dengan kualifikasi Baik dengan jumlah guru memperoleh nilai Amat Baik dan Baik
$100 \%$ di SD Negeri 2 Gambiranom semester 1 Tahun Pelajaran 2018/2019.

\section{KESIMPULAN}

Berdasarkan hasil penelitian maka kesimpulan dalam penelitian ini yaitu kegiatan supervisi akademik secara periodik dapat meningkatkan kompetensi guru dalam menyusun RPP di SD Negeri 2 Gambiranom semester 1 Tahun Pelajaran $2018 / 2019$.

\section{DAFTAR PUSTAKA}

Alfonso, Robert J., Firth. G. R. dand Neville, R. 1981,. Instructional. Supervision : A Behavior System. Allyn and Bacon Inc. Boston.

Asep Herry Hermawan,dkk .(2009). Pengembangan Kurikulum dan Pembelajaran. Jakarta : Universitas Terbuka.

Depdiknas. 2008. Peraturan Pemerintah RI No.19 Tahun 2005 tentang Standar. Nasional Pendidikan. Jakarta: Depdiknas.

Mahmuda, T. (2013). Penyusunan Rencana Pelaksanaan Pembelajaran (RPP) Guru Bhasa Indonesia di SMP N 2 BANTUL. Journal of Chemical Information and Modeling, 53(9), 1689-1699.

Mahmuda, T. (2013). Penyusunan Rencana Pelaksanaan Pembelajaran (RPP) Guru Bhasa Indonesia di SMP N 2 BANTUL. Journal of Chemical Information and Modeling, 53(9), 1689-1699.

Nurgiansah, T. H. (2021). Pelatihan Penelitian Tindakan Kelas Bagi Guru Pendidikan Kewarganegaraan Di Sekolah Menengah Atas Se-Kabupaten Bantul. BERNAS: Jurnal Pengabdian Kepada Masyarakat, 2(1), 28-33. https://doi.org/10.31949/jb.v2i1.566

Nurgiansah, T. H., \& Sukmawati. (2020). Tantangan Guru Pendidikan Kewarganegaraan Di Masa Adaptasi Kebiasaan Baru. Jurpis: Jurnal Pendidikan Ilmu Sosial, 17(2), 139-149.

Oviana, W. (2013). Pengembangan Rencana Pelaksanaan Pembelajaran Berbasis Pendekatan Saintifik Oleh Guru SD dan MI di Kota Sabang. Journal of Chemical Information and Modeling, 2(9), 1689-1699.

Rahayu, Y. M. (2016). Pengaruh perubahan kurikulum 2013 terhadap perkembangan peserta didik. Jurnal Logika, XVIII(3), 22-42.

Sahertian, Piet A. 2000. Konsep Dasar dan Teknik Supervisi akademik. Jakarta: Rineka Cipta.

Sudjana, Nana. 2012. Penelitian Hasil Proses Belajar Mengajar. Bandung: Remaja Rosda Karya

Suharsimi Arikunto. 2004. Dasar-Dasar Evaluasi Pendidikan. Jakarta: Bumi Aksara.

Sulastri, S., Imran, I., \& Firmansyah, A. (2014). Meningkatkan hasil belajar siswa melalui strategi pembelajaran berbasis masalah pada mata pelajaran IPS di. Jurnal Kreatif Online, 3(1).

Yaumi dan Ibrahim. 2013. Pembelajaran Berbasis Kecerdasan Jamak. Jakarta: Prenadamedia Group. 